\title{
BUDIDAYA ULAT SUTERA DI DESA SUDU, KECAMATAN ALLA, KABUPATEN ENREKANG, SULAWESI SELATAN
}

\author{
(Silkworm Rearing at Sudu Village, Alla District, \\ Enrekang Regency, South Sulawesi)
}

\author{
Nurhaedah M. dan/and Achmad Rizal H. Bisjoe \\ Balai Penelitian Kehutanan Makassar \\ Jl. Perintis Kemerdekaan Km. 16,5 Makassar 90243 \\ Telp. 0411-554049; Fax. 0411-554058
}

Naskah masuk : 6 Januari 2013; Naskah diterima : 19 November 2013

\begin{abstract}
This research aims to know silkworm rearing and source of food at Sudu Village, Alla District, Enrekang Regency, South Sulawesi. The data was collected by applying survey method and interviewing the silk farmers. Furthermore, observation was conducted in elaborating the characteristics offarmers, silkworm, biophysical characteristics, and cultivation of mulberry plants. The collected data were analyzed descriptively. The result showed that the management pattern of mulberry cultivation and silkworm rearing at research location majority (75\%) was based on the experience of farmers. The standard recommended by the related agency dealing with silk, such as determining plant spacing, low prunning techniques, frequency offeeding, disinfection, and feeding techniques, was not applied yet. Although the hovels were built to rear the silkworm and placed around the mulberry garden with the rearing period ranges from 27-29 days, the production of cocoons was lesser than the recommended standard. In regard to this fact, it needs to adopt the standard technology of mulberry cultivation and silkworm rearing as well by considering the condition of location.
\end{abstract}

Keywords: Rearing, silkworm, Sudu Village, Enrekang Regency

\begin{abstract}
ABSTRAK
Penelitian bertujuan untuk mengetahui pola budidaya ulat sutera dan sumber pakannya di Desa Sudu, Kecamatan Alla, Kabupaten Enrekang, Sulawesi Selatan. Pengumpulan data dilakukan melalui metode survei dengan wawancara langsung terhadap petani. Pengamatan dilakukan terhadap karakteristik petani, kegiatan budidaya ulat sutera, karakteristik biofisik, dan budidaya tanaman murbei. Data yang terkumpul dianalisis melalui analisis perbandingan secara deskriptif. Hasil penelitian menunjukkan bahwa budidaya murbei dan ulat sutera di lokasi penelitian sebagian besar $(75 \%)$ didasarkan pada pengalaman petani. Petani belum menerapkan standar yang direkomendasikan oleh instansi yang khusus menangani persuteraan alam, seperti penentuan jarak tanam, teknik pemangkasan rendah, frekuensi pemberian pakan, desinfeksi, dan teknik pemberian pakan. Sekalipun petani sudah menggunakan rumah ulat sebagai tempat pemeliharaan yang ditempatkan di sekitar kebun murbei dalam waktu pemeliharaan berkisar 27-29 hari, tetapi jumlah kokon yang dihasilkan lebih rendah dibanding standar yang direkomendasikan. Sehubungan dengan keadaan tersebut, perlu diadopsi teknologi standar untuk budidaya murbei dan ulat sutera dengan mempertimbangkan kondisi lokasi.
\end{abstract}

\section{PENDAHULUAN}

\section{A. Latar Belakang}

Sutera alam bagi daerah Sulawesi Selatan merupakan sumberdaya kehutanan non kayu yang amat potensial dan merupakan salah satu komoditas andalan daerah. Sutera alam sudah merupakan budaya yang melekat dengan masyarakat Sulawesi Selatan. Sampai saat ini Sulawesi Sela$\tan$ merupakan daerah penghasil sutera terbesar di Indonesia, namun hampir seluruh sistem usaha persuteraan alam masih dikelola secara tradisional, berskala kecil, dan berpola subsisten.

Luasan lahan murbei di Sulawesi Selatan sebagai pakan ulat sutera adalah 1.713 hektar dan dikelola oleh 3.214 kepala keluarga (Balai Persuteraan Alam, 2008). Produksi benang sutera Sulawesi Selatan masih merupakan yang terbesar di Indonesia dengan produksi 54,3 ton atau $84,8 \%$ dari 64,02 ton produksi nasional. Namun, 
terdapat beberapa hal yang masih perlu mendapat perhatian serius dalam usaha persuteraan alam di Sulawesi Selatan, yaitu 1) kegiatan usaha persuteraan alam sebagian besar merupakan usaha sampingan, 2) usaha budidaya sutera belum sepenuhnya mengikuti standar yang dianjurkan (Nurhaedah et al., 2006). Bahkan saat ini kegiatan usaha persuteraan alam di Sulawesi Selatan cenderung semakin ditinggalkan oleh para petani. Hal ini dapat dilihat dari konversi lahan tanaman murbei menjadi komoditas lain yang lebih menguntungkan.

Dalam upaya pengembangan persuteraan alam di Sulawesi Selatan, terdapat banyak faktor yang perlu ditingkatkan mulai dari aspek hulu (budidaya ulat sutera), aspek produksi pemintalan dan pertenunan hingga aspek pemasaran produk. Kegiatan di sektor hulu yang terjadi di lokasi pemeliharaan ulat sutera di Sulawesi Selatan terbagi atas daerah dataran rendah, sedang dan tinggi. Perbedaan lokasi dapat mengakibatkan adanya perbedaan produktivitas ulat sutera akibat perbedaan iklim mikro dan ketinggian tempat untuk produktivitas daun murbei sebagai pakan ulat sutera (Nurhaedah et al., 2006).

Selama ini budidaya ulat sutera yang direkomendasikan masih bersifat umum, sementara kondisi lokasi di Sulawesi Selatan cukup bera- gam. Pedoman teknis budidaya ulat sutera yang tersedia belum sesuai kondisi lokasi. Diharapkan melalui penelitian dapat disajikan data dan informasi sebagai bahan pertimbangan dalam menyusun pedoman budidaya ulat sutera yang spesifik sesuai dengan kondisi lokasi.

\section{B. Tujuan Penelitian}

Tujuan penelitian adalah untuk mengetahui pola usaha budidaya ulat sutera pada daerah dataran sedang berkisar $500 \mathrm{~m}$ dpl di Kabupaten Enrekang, Sulawesi Selatan. Informasi ini diharapkan bermanfaat sebagai dasar untuk penyusunan pedoman budidaya ulat sutera yang spesifik lokasi dan dapat diterapkan sesuai kondisi lokasi tersebut.

\section{METODE PENELITIAN}

\section{A. Lokasi Penelitian}

Penelitian dilaksanakan di Desa Sudu, Kecamatan Alla, Kabupaten Enrekang, Sulawesi Selatan. Lokasi terletak pada ketinggian 500 meter di atas permukaan laut (dpl) yang termasuk dataran sedang, dengan suhu berkisar $23-27^{\circ} \mathrm{C}$, kelembaban berkisar $70-80 \%$. Peta lokasi penelitian disajikan pada Gambar 1.

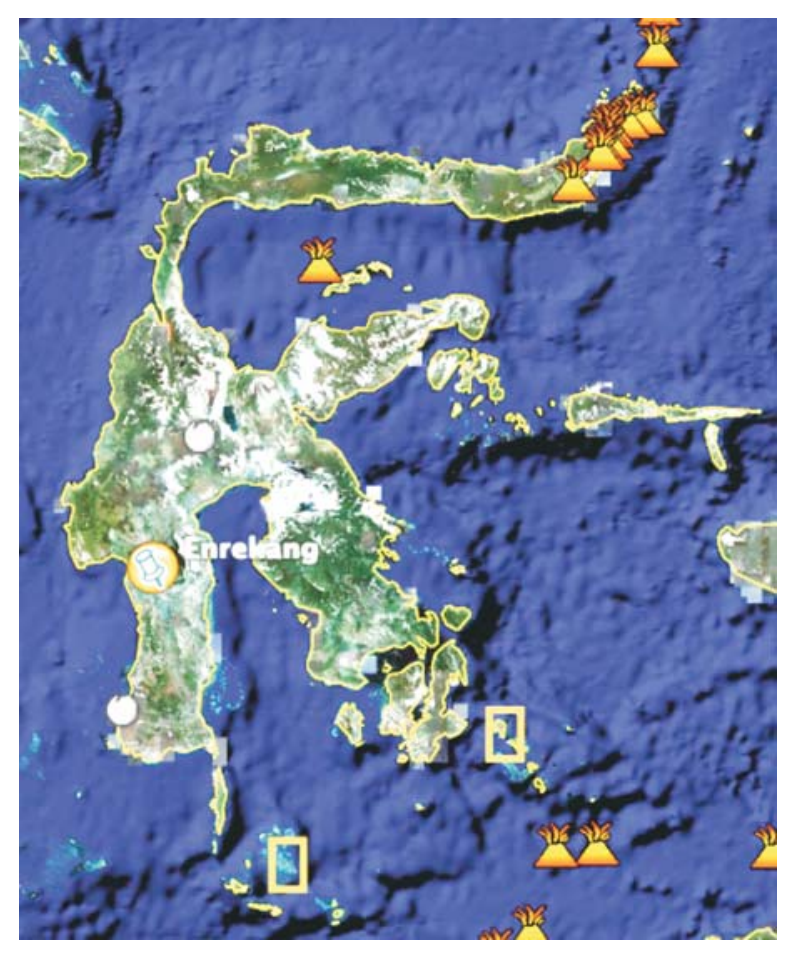

Gambar (Figure) 1. Peta lokasi penelitian (Research location map) (Sumber: http://www.google.com) 


\section{B. Bahan dan Alat}

Bahan dan alat yang digunakan dalam penelitian adalah: kuesioner, alat perekam, dan alat tulis.

\section{Pengumpulan dan Analisis Data}

Pengumpulan data dilakukan dengan menggunakan metode survei dengan mewawancarai 20 responden yang intensif melakukan budidaya ulat murbei dan ulat sutera secara purposif. Data primer berupa: kondisi sosial ekonomi petani, kondisi kegiatan budidaya ulat sutera dan budidaya tanaman murbei, dikumpulkan dengan menggunakan daftar pertanyaan kuesioner dan wawancara langsung dengan petani. Data sekunder berupa kondisi fisik wilayah diperoleh dari Balai Persuteraan Alam dan Dinas Kehutanan serta instansi terkait di Kabupaten Enrekang. Variabel pengamatan, antara lain: karakteristik petani dan budidaya ulat sutera, karakteristik biofisik, dan karakteristik budidaya tanaman murbei. Tolok ukur produktivitas dapat dilihat dari kualitas dan kuantitas yang dihasilkan (Omura, 1980).

Hasil pengumpulan data di lapang kemudian ditabulasi dan dianalisis secara deskriptif kualitatif melalui analisis perbandingan antara kondisi budidaya ulat sutera berdasarkan standar yang direkomendasikan dengan kondisi budidaya ulat sutera di lokasi penelitian. Sejauh ini belum tersedia pedoman khusus budidaya ulat sutera. Oleh karena itu, digunakan nilai standar yang diperoleh dari berbagai pustaka terkait budidaya ulat sutera yang telah dipraktikkan secara umum.

\section{HASIL DAN PEMBAHASAN}

\section{A. Kondisi Biofisik}

Kondisi biofisik lokasi yang berpengaruh dalam budidaya ulat sutera adalah suhu, kelembaban nisbi, kualitas udara, aliran udara, dan cahaya. Hal ini sangat penting untuk menyesuaikan iklim mikro di tempat pemeliharaan, agar cocok dengan pertumbuhan masing-masing instar ulat sutera, serta dapat memproduksi kokon sebanyak mungkin (Atmosoedarjo et al., 2000).

Menurut Syamsijah dan Lincah (1992) kondisi yang ideal untuk budidaya ulat sutera adalah suhu berkisar antara $20-23^{\circ} \mathrm{C}$ dan kelembaban berkisar antara $70-85 \%$. Hal ini menggambarkan bahwa wilayah ini mendekati kondisi optimal untuk budidaya ulat sutera, karena menurut Direktorat Jenderal Rehabilitasi Lahan dan Perhutanan Sosial (2006), secara agroklimat beberapa lokasi pengembangan kegiatan budidaya sutera di Indonesia kurang sesuai untuk pertumbuhan ulat sutera (bivoltine).

Menurut Atmosoedarjo et al. (2000) budidaya ulat sutera cocok dilakukan pada ketinggian berkisar 300-800 m dpl. Dengan demikian, Kabupaten Enrekang dengan ketinggian sekitar $500 \mathrm{~m}$ dpl termasuk wilayah yang ideal untuk budidaya ulat sutera dan berpengaruh baik terhadap kualitas dan kuantitas kokon yang dihasilkan. Kondisi biofisik juga berpengaruh terhadap lamanya waktu pemeliharaan ulat, ukuran dan berat kokon yang dihasilkan, dan pada akhirnya berpengaruh pada harga kokon/kg.

\section{B. Kondisi Sosial Ekonomi Petani}

Kondisi umum petani di Desa Sudu, Kecamatan Alla, Kabupaten Enrekang dikaji dalam indikator umur, tingkat pendidikan, dan kategori pekerjaan pokok dan sampingan bagi setiap pelaku budidaya ulat. 
Tabel (Table) 1. Kondisi petani di Desa Sudu, Kecamatan Alla, Kabupaten Enrekang (Farmer condition at Sudu Village, Alla District, Enrekang Regency)

\begin{tabular}{|c|c|c|c|}
\hline No. & $\begin{array}{c}\text { Kondisi petani } \\
\text { (Farmer condition) }\end{array}$ & $\begin{array}{l}\text { Hasil pengamatan } \\
\text { (Observation data) }\end{array}$ & $\begin{array}{c}\text { Standar rekomendasi } \\
\text { (Recommended standard) }\end{array}$ \\
\hline 1. & Umur rata-rata (Average age) & : 34 tahun & Umur produktif \\
\hline & Pendidikan (Education) & & \\
\hline & - Tak tamat SD & $: \quad-$ & Minimal SD \\
\hline & - Tamat SD & $: \quad-$ & \\
\hline & - SLTP & $: \quad-$ & \\
\hline & - SLTA & $: \quad 100 \%$ & \\
\hline 3. & Pekerjaan pokok (Main job) & $\begin{array}{l}\text { : Petani sawah (Rice field } \\
\text { farmer), } \\
\text { Pedagang (Trader) }\end{array}$ & Sesuai kondisi \\
\hline & $\begin{array}{l}\text { Pekerjaan Sampingan } \\
\text { (Secondary job) }\end{array}$ & : Petani sutera (Silk farmer) & Sesuai kondisi \\
\hline
\end{tabular}

Sumber (Source) : Data primer diolah, 2006 (Primary data processed, 2006)

Dalam melakukan budidaya ulat sutera, umur petani biasanya menjadi salah satu faktor yang menentukan produksi kokon yang dihasilkan. Umur diidentikkan dengan kemampuan seseorang dalam melakukan usaha atau kegiatan yang dapat mempengaruhi produktivitas kerja (Tohir, 1995). Kondisi umur petani di Desa Sudu, Kecamatan Alla, Kabupaten Enrekang adalah rata-rata termasuk angkatan kerja muda, yaitu 34 tahun. Faktor umur biasanya menjadi salah satu faktor penentu dalam keberhasilan budidaya ulat sutera, karena angkatan kerja muda biasanya lebih kreatif dan inovatif.

Tingkat pendidikan yang dimiliki oleh seorang petani secara tidak langsung akan berpengaruh pada kualitas produk yang dihasilkan, karena hal ini dapat berpengaruh pada kemampuan menyerap dan menerima inovasi baru termasuk teknologi dan informasi. Rata-rata tingkat pendidikan petani di lokasi penelitian sudah memenuhi standar yaitu tamat SLTA.

Pekerjaan masyarakat di lokasi penelitian dapat dibagi atas pekerjaan pokok dan pekerjaan sampingan. Pekerjaan pokok masyarakat adalah petani sawah dengan komoditas padi dan sayursayuran serta berdagang. Sedangkan kegiatan budidaya sutera merupakan pekerjaan sampingan. Hal ini disebabkan karena bertani merupakan pekerjaan yang sudah menjadi tradisi yang sudah turun-temurun sedangkan berdagang lebih menjanjikan keuntungan, didukung oleh akses pasar yang dekat di sekitar lokasi serta risikonya lebih kecil dibandingkan budidaya ulat sutera.

\section{Budidaya tanaman murbei}

Budidaya tanaman murbei sangat erat kaitannya dengan budidaya ulat sutera, karena keberhasilan budidaya ulat sutera sangat tergantung pada kualitas murbei sebagai satu-satunya jenis tanaman pakan bagi ulat sutera. Budidaya murbei memerlukan penanganan khusus mulai dari pengadaan bibit, penanaman dan pemeliharaan, pengendalian hama dan penyakit serta pemungutan dan penyimpanan daun (Sunanto, 1997). 
Tabel (Table) 2. Kondisi budidaya tanaman murbei di Desa Sudu, Kecamatan Alla, Kabupaten Enrekang (The Condition of mulberry cultivation at Sudu Village, Alla District, Enrekang Regency)

\begin{tabular}{|c|c|c|c|c|}
\hline No. & $\begin{array}{l}\text { Kondisi budidaya murbei } \\
\text { (The condition of mulberry } \\
\text { cultivation) }\end{array}$ & & $\begin{array}{l}\text { Hasil pengamatan } \\
\text { (Observation data) }\end{array}$ & $\begin{array}{l}\text { Standar rekomendasi } \\
\text { (Recommended standard) }\end{array}$ \\
\hline 1. & $\begin{array}{l}\text { Luas lahan rata-rata (Land width } \\
\text { average) }\end{array}$ & : & 0,71 ha & $0,25-1$ ha \\
\hline 2. & $\begin{array}{l}\text { Status lahan (Land status) } \\
\text { - Milik sendiri } \\
\text { - Sewa }\end{array}$ & : & $\begin{array}{l}75 \% \\
25 \%\end{array}$ & milik sendiri \\
\hline 3. & Jenis murbei (Mulberry species) & : & $\begin{array}{l}\text { M.nigra, M.alba, } \\
\text { M.indica }\end{array}$ & $\begin{array}{l}\text { M.nigra, M.alba, } \\
\text { M.indica }\end{array}$ \\
\hline 4. & Jarak tanam (Plant spacing) & : & $30 \times 30 \mathrm{~cm}$ & $100 \times 50 \mathrm{~cm}$ \\
\hline 5. & $\begin{array}{l}\text { Umur tanaman tata-rata (Plant age) } \\
\text { Pemeliharaan tanaman (Plant } \\
\text { cultivation) }\end{array}$ & : & 13 tahun & $<25$ tahun \\
\hline & $\begin{array}{l}\text { - Pemangkasan (Prunning) } \\
\text { - Pemupukan (Fertilization) } \\
\text { - Pencegahan hama penyakit (Pest } \\
\text { and disease prevention) }\end{array}$ & $\begin{array}{l}: \\
: \\
:\end{array}$ & $\begin{array}{l}5-6 \mathrm{kali} / \text { tahun } \\
6 \mathrm{kali} / \text { tahun } \\
1 \mathrm{kali} / \text { tahun }\end{array}$ & $\begin{array}{l}6 \mathrm{kali} / \mathrm{tahun} \\
\text { setelah panen daun } \\
\text { sesuai kondisi }\end{array}$ \\
\hline
\end{tabular}

Sumber (Source) : Data primer diolah, 2006 (Primary data processed, 2006)

Data Tabel 2 menunjukkan bahwa rata-rata luas lahan murbei yang dikelola petani sudah sesuai dengan standar yang direkomendasikan. Demikian pula dari segi kepemilikan lahan dan jenis murbei yang diusahakan. Meskipun saat ini terdapat jenis murbei hasil persilangan yaitu NI (hasil persilangan M. nigra dan M. indica, namun informasi ini belum sepenuhnya diketahui oleh masyarakat.

Jarak tanam yang digunakan masyarakat berbeda dengan dengan standar. Penggunaan jarak tanam rapat tersebut diterapkan masyarakat karena beberapa pertimbangan. Salah satu diantaranya adalah untuk menghindari percikan air ke daun yang mempengaruhi kualitas daun sebagai pakan dan mengurangi pertumbuhan gulma yang dapat mempengaruhi produktivitas tanaman murbei. Jenis yang digunakan untuk jarak tanam rapat pada umumnya jenis $M$. indica yang berdaun agak lebar.

Dilihat dari rata-rata umur tanaman yang dimiliki petani, ternyata tanaman murbei di lokasi penelitian rata-rata berumur 13 tahun. Jika dibandingkan standar yang direkomendasikan yaitu umur produktif tanaman murbei dapat mencapai 25 tahun, maka tanaman murbei di daerah ini masih tergolong produktif. Hal ini penting mengingat umur tanaman secara langsung berhubungan dengan produktivitas tanaman dan produksi kokon.
Selain aspek-aspek di atas, yang juga dikaji adalah pemeliharaan tanaman. Menurut Atmosoedarjo et al. (2000) pemeliharaan tanaman meliputi penyiangan, pendangiran, pemupukan, pemangkasan, dan pengendalian hama dan penyakit.

Frekuensi pemangkasan yang dilakukan sudah sesuai dengan standar yang dianjurkan. Pemangkasan biasanya dilakukan setelah panen daun, dan dilanjutkan dengan pemupukan.

Dilihat dari frekuensi pemupukan, masyarakat di lokasi penelitian melakukan pemupukan rata-rata di atas 5 kali setahun yang berarti sudah sesuai dengan standar yaitu setelah panen daun. Panen daun terkait dengan frekwensi pemeliharaan yaitu 6 kali/tahun (Tabel 3). Selain itu juga terkait dengan jarak tanam yang rapat sehingga untuk mempertahankan kesuburan tanah diperlukan pemupukan yang lebih banyak.

Salah satu aspek penting dalam budidaya tanaman murbei adalah pengendalian hama dan penyakit. Berdasarkan kajian yang dilakukan terlihat bahwa frekuensi pengendalian hama dan penyakit pada lokasi penelitian hanya berkisar 1 kali setahun dan sudah sesuai dengan standar yaitu disesuaikan dengan tingkat serangan hama penyakit. Meskipun ada serangan kalau belum melewati ambang ekonomi atau secara ekonomi belum merugikan, tidak perlu dilakukan pengendalian untuk efisiensi biaya produksi. 
Pola-pola pengelolaan seperti jarak tanam rapat dan pangkasan pendek dilakukan masyarakat di lokasi penelitian, karena menurut mereka hal ini lebih menguntungkan dari sisi ekonomi karena mengurangi pertumbuhan gulma dan serangan penyakit pada tanaman murbei.

\section{Proses produksi ulat sutera}

Tahap lanjut dari pembibitan ulat sutera adalah pemeliharaan atau budidaya ulat sutera. Menurut Balai Persuteraan Alam (1997), teknik budidaya ulat sutera yang direkomendasikan terbagi dalam 3 tahap, yaitu:

\section{a. Penanganan telur ulat sutera}

Setelah telur terlihat titik biru, maka diadakan perlakuan penggelapan dan penerangan terhadap telur tersebut. Hal ini dilakukan untuk mendapatkan penetasan telur yang merata (seragam). Setelah telur menetas dilakukan desinfeksi kaporit dengan konsentrasi 5\% dicampur kapur 95\%, waktu pelaksanaan sekitar pukul 9.00 pagi. Pemberian pakan dilakukan dengan daun murbei muda yang dipotong sekitar (5 x 5) mm sebanyak 100 gr setiap kotak telur.

\section{b. Pemeliharaan ulat kecil}

Kondisi lingkungan yang baik untuk ulat kecil adalah suhu $26-28^{\circ} \mathrm{C}$ dengan kelembaban 80 $90 \%$. Pemberian pakan dilakukan dengan daun murbei yang dipotong-potong atau dirajang antara 0,5-3 cm sebanyak 3-4 kali sehari pada pagi, siang, sore, dan malam hari. Pemberian desinfeksi berupa kaporit dengan konsentrasi 5\% dicampur kapur 95\%, dilakukan apabila sebagian besar (90\%) ulat telah berganti kulit. Perluasan tempat ulat dilakukan sesuai dengan perkembangan ulat.

\section{c. Pemeliharaan ulat besar}

Kondisi lingkungan yang baik untuk ulat besar adalah suhu antara $24-26{ }^{\circ} \mathrm{C}$ dengan kelembaban berkisar 70-75\%. Ulat besar memerlukan daun murbei yang berumur pangkas kurang lebih 2,5-3 bulan. Pemberian pakan dilakukan sebanyak 3-4 kali sehari, pemberian daun dengan cabangnya diletakkan secara bolak balik agar distribusi daun merata. Tempat ulat dan rak pemeliharaan perlu sering dibersihkan dan diperluas sesuai dengan perkembangan ulat. Desinfeksi ulat dilakukan setelah ulat berganti kulit dengan campuran kaporit dan kapur sebanyak 1 : 9 (10 gr kaporit : 90 gr kapur). Di samping desinfeksi ulat, juga perlu dilakukan desinfeksi alat dan ruang pemeliharaan dengan menggunakan larutan desinfeksi dengan dosis 200 kali atau 5 gr kaporit per liter air. Pada akhir instar V, sekitar 21 hari sejak ulat mulai dipelihara, ulat akan mulai membuat kokon. Panen dilakukan pada hari ke5 atau ke-6 sejak ulat mulai membuat kokon.

Keberhasilan pemeliharaan ulat dipengaruhi oleh banyak faktor diantaranya kualitas dan kuantitas daun murbei, jenis bibit, dan teknik pemeliharaan (Samsijah dan Lincah, 1992). Faktor-faktor tersebut saling terkait dan sangat diperlukan agar pemeliharaan ulat sutera dapat menghasilkan kokon dengan jumlah yang banyak dan mutu yang baik. Beberapa kriteria kondisi budidaya ulat sutera yang dilakukan petani di lokasi penelitian disajikan pada Tabel 3 . 
Tabel(Table) 3. Kondisi budidaya ulat sutera di Desa Sudu, Kecamatan Alla, Kabupaten Enrekang (The condition of silkworm rearing at Sudu Village, Alla District, Enrekang Regency)

\begin{tabular}{|c|c|c|c|c|c|}
\hline No. & $\begin{array}{l}\text { Kondisi budidaya ulat sutera } \\
\text { (The condition of silkworm } \\
\text { rearing) }\end{array}$ & & $\begin{array}{l}\text { Hasil pengamatan } \\
\text { (Observation data) }\end{array}$ & & $\begin{array}{c}\text { Standar rekomendasi } \\
\text { (Recommended standard) }\end{array}$ \\
\hline 1. & $\begin{array}{l}\text { Jumlah bibit (kotak) } \\
\text { (Number of seedlings) (box) }\end{array}$ & $:$ & 1,5 & $:$ & 1 - 1,5 kotak/periode \\
\hline 2. & $\begin{array}{l}\text { Sumber bibit ( Source of } \\
\text { seedlings) }\end{array}$ & : & $100 \%$ & : & Perum Perhutani \\
\hline & $\begin{array}{l}\text { - Perum perhutani } \\
\text { - Lainnya }\end{array}$ & : & - & & \\
\hline \multirow[t]{4}{*}{3.} & $\begin{array}{l}\text { Pengetahuan budidaya sutera } \\
\text { (Knowledge of silkworm rearing) }\end{array}$ & & & & \\
\hline & - Turun-temurun & . & $75 \%$ & $:$ & pengalaman diperkaya \\
\hline & - Belajar sendiri & : & $25 \%$ & & pengetahuan dan \\
\hline & - Lainnya & : & $0 \%$ & & keterampilan \\
\hline \multirow[t]{3}{*}{4.} & $\begin{array}{l}\text { Tempat pemeliharaan (Rearing } \\
\text { area) }\end{array}$ & & & & \\
\hline & - Kolong rumah (Basement) & : & $50 \%$ & : & rumah ulat \\
\hline & - Rumah ulat (Larva house) & : & $50 \%$ & & \\
\hline \multirow[t]{2}{*}{5.} & Tenaga kerja (Labor) & & & & \\
\hline & $\begin{array}{l}\text { - Keluarga (Family) } \\
\text { - Upahan (Wages) }\end{array}$ & : & $\begin{array}{l}100 \% \\
-\end{array}$ & $:$ & sesuai kondisi \\
\hline 6. & $\begin{array}{l}\text { Frekuensi pemeliharaan } \\
\text { (Frequency of rearing) }\end{array}$ & : & $6 \mathrm{kali} / \mathrm{tahun}$ & : & 6 kali/tahun \\
\hline 7. & $\begin{array}{l}\text { Alat pemeliharaan ulat kecil } \\
\text { (Rearing equipment for young } \\
\text { larva) }\end{array}$ & $:$ & $\begin{array}{l}\text { tempat inkubasi, } \\
\text { nampan, jaring, } \\
\text { pemotong daun }\end{array}$ & : & $\begin{array}{l}\text { tempat inkubasi, nampan, } \\
\text { jaring, kuas, pemotong } \\
\text { daun }\end{array}$ \\
\hline 8. & $\begin{array}{l}\text { Alat pemeliharaan ulat besar } \\
\text { (Rearing equipment for adult } \\
\text { larva) }\end{array}$ & : & $\begin{array}{l}\text { sasag,rak,alat } \\
\text { desinfeksi, } \\
\text { pengokonan }\end{array}$ & & $\begin{array}{l}\text { alat pemeliharaan, } \\
\text { desinfeksi, pengokonan }\end{array}$ \\
\hline 9. & $\begin{array}{l}\text { Frekuensi pemberian pakan } \\
\text { (feeding frequency) }\end{array}$ & : & 2 kali/hari & & 3-4 kali/hari \\
\hline \multirow[t]{3}{*}{10.} & Desinfeksi (Desinfection) & & & & \\
\hline & - Bahan (Material) & r. & kapur, kaporit & : & kapur, kaporit \\
\hline & $\begin{array}{l}\text { - Frekuensi/periode pemeliharaan } \\
\text { (rearing frequency) }\end{array}$ & . & 2 kali & : & 2 kali \\
\hline 11. & $\begin{array}{l}\text { Teknik pemberian pakan } \\
\text { (feeding tecnique) }\end{array}$ & : & daun dengan tangkai & : & daun dengan tangkai \\
\hline \multirow{2}{*}{$\begin{array}{c}12 . \\
13 .\end{array}$} & $\begin{array}{l}\text { Pemisahan jenis pakan } \\
\text { (feeding selection) }\end{array}$ & : & tidak ada pemisahan & : & ada pemisahan \\
\hline & $\begin{array}{l}\text { Pengokonan(Cocooning) } \\
\text { - Jenis alat (Types of tools) } \\
\text { - Perlakuan (Treatment) }\end{array}$ & $:$ & $\begin{array}{l}\text { plastik, bambu } \\
\text { ruang ulat ditutup }\end{array}$ & $:$ & $\begin{array}{l}\text { plastik, bambu, karton } \\
\text { perlindungan,cahaya } \\
\text { kurang }\end{array}$ \\
\hline 14. & $\begin{array}{l}\text { Jumlah produksi rata-rata } \\
\text { (Production average) }\end{array}$ & & & & \\
\hline \multirow[b]{2}{*}{15.} & - Kokon (Coocon) & . & $20-40 \mathrm{~kg} / \mathrm{kotak}$ & $:$ & 30-40 kg/kotak (telur) \\
\hline & $\begin{array}{l}\text { Waktu pemeliharaan ulat (Rearing } \\
\text { duration of larva) }\end{array}$ & : & 27-29 hari & : & sesuai iklim \\
\hline
\end{tabular}

Sumber (Source) : Data primer diolah, 2006 (Primary data processed, 2006) 
Besarnya jumlah bibit ulat sutera yang dipelihara dipengaruhi oleh luasan tanaman murbei yang dikelola, kapasitas rumah ulat, dan jumlah tenaga kerja yang digunakan. Jumlah bibit yang dipelihara sudah sama dengan standar, namun jika dihubungkan dengan rata-rata luas tanaman murbei yang dikelola yaitu 0,71 hektar maka pengelolaan masih dapat ditingkatkan, karena kebutuhan pakan ulat untuk 1 kotak telur adalah rata-rata 0,25 ha (Maturidy, 2011).

Dilihat dari sumber bibit ulat sutera yang digunakan, saat penelitian berlangsung di lokasi penelitian seluruhnya (100\%) menggunakan bibit Perum Perhutani sesuai standar yang dianjurkan pemerintah. Pembuatan bibit lokal sebetulnya dilarang pemerintah karena dikhawatirkan dapat memacu timbulnya serangan penyakit.

Tempat petani melakukan budidaya ulat sutera sedikit banyak akan berpengaruh terhadap tahapan kegiatan yang dilakukan dan jumlah kokon yang dihasilkan. Pengamatan yang dilakukan pada lokasi penelitian menunjukkan bahwa $50 \%$ masyarakat sudah mengikuti standar yaitu memiliki rumah ulat khusus untuk peme-liharaan ulat yang berdampingan dengan kebun murbei, namun 50\% masih menggunakan kolong rumah. Menurut Rasyid (1996) bahwa pemeliharaan ulat seharusnya terpisah dari aktivitas manusia sehari-hari.

Sumber tenaga kerja yang digunakan pada umumnya adalah tenaga kerja keluarga. Melalui wawancara diketahui bahwa mereka tidak sepenuhnya mengerjakan sendiri budidaya ulat sutera, tetapi seringkali dibantu oleh tetangga kebun secara gotong royong.

Frekuensi pemeliharaan adalah jumlah pemeliharaan yang dapat dilakukan dalam jangka waktu setahun. Frekwensi pemeliharaan sudah sesuai standar yaitu 6 kali setahun. Frekwensi yang tidak terlalu padat memberi kesempatan untuk merawat kebun dan memutus siklus penyakit yang ada saat pemeliharaan ulat berlangsung.

Peralatan pemeliharaan yang digunakan pada lokasi penelitian menunjukkan bahwa baik untuk pemeliharaan ulat kecil maupun ulat besar umumnya sudah golong standar atau sesuai dengan yang direkomendasikan Balai Persuteraan Alam (1997), yaitu rak kayu/bambu, pisau, jaring, bulu ayam, kertas alas, kertas minyak, gunting stek, baskom dan ember plastik, kain pembungkus daun, ayakan, kapur dan kaporit, sapu, lap tangan dan sprayer untuk desinfeksi ruangan dan alat.

Frekuensi pemberian pakan adalah jumlah pemberian pakan yang dilakukan dalam jangka waktu sehari. Frekuensi pemberian pakan yang dilakukan oleh masyarakat pada umumnya hanya 2 kali, yaitu pagi dan sore hari, sedangkan pemberian pakan yang direkomendasikan Balai Persuteraan Alam (1997) adalah 3-4 kali sehari. Rata-rata petani menerapkan pemberian pakan 2 kali dengan alasan bahwa meskipun 2 kali tetapi volume pemberian ditingkatkan. Dilihat dari kondisi fisik wilayah, pemberian pakan dengan volume yang ditingkatkan dapat saja diterapkan di Kabupaten Enrekang karena daun tidak cepat layu. Pemberian pakan 3 kali yang ditunjang kondisi biofisik yang optimal dapat meningkatkan produktivitas ulat sutera.

Desinfeksi adalah suatu kegiatan yang dilakukan untuk membersihkan dan mencegah serangan hama penyakit baik sebelum, selama maupun setelah pemeliharaan. Desinfeksi tidak hanya bagi ulat sutera, tetapi juga peralatan pemeliharaan dan rumah ulat. Khusus untuk desinfeksi tubuh ulat sutera biasanya dilakukan dengan menggunakan bahan kapur dan kaporit. Pemberian desinfeksi bagi tubuh ulat biasanya dilakukan pada saat hakitate (pemberian pakan pertama setelah menetas), ulat tidur, dan setelah ulat berganti kulit. Di lokasi penelitian pemberian desinfeksi rata-rata adalah 2 kali, lebih rendah dibanding yang direkomendasikan Balai Persuteraan Alam (1997), yaitu sebanyak 3 kali. Padahal, semestinya daerah dataran sedang dengan kondisi yang lebih lembab, pemberian desinfeksi diperlukan lebih banyak karena kondisi yang lembab dapat memacu terjadinya serangan penyakit pada ulat sutera (Sunanto, 1997).

Teknik pemberian pakan yang dilakukan sudah memenuhi standar atau sesuai anjuran. Pemberian pakan ulat kecil dilakukan dengan metode rajang menggunakan daun pucuk atau daun yang muda, sedang untuk ulat besar pemberian dilakukan dengan tangkai yang diberikan secara berselang-seling agar ulat mendapatkan pakan yang merata antara pucuk dan yang bukan pucuk. Namun, masyarakat di lokasi penelitian tidak menerapkan pemisahan jenis murbei maupun kebun untuk pakan ulat kecil dan ulat besar, padahal pengelolaan kebun dan jenis pakan yang tepat dapat meningkatkan produktivitas ulat sutera. Menurut Atmosoedarjo et al. (2000) kesehatan ulat sutera tergantung pada pemberian pakan ulat waktu kecil, karena itu perlu membuat kebun murbei khusus untuk ulat kecil yang diberi perlakuan khusus untuk menghasilkan tunastunas baru dalam jumlah besar dan mudah dipungut.

Tahap pengokonan adalah merupakan tahap akhir dalam budidaya ulat sutera, sehingga pena- 
nganannya harus hati-hati. Bila tahap ini tidak dilaksanakan dengan baik, maka akan berpengaruh pada kualitas filamen kokon dan pekerjaan yang telah dilakukan sebelumnya akan menjadi sia-sia (Atmosoedarjo et al., 2000). Alat pengokonan yang digunakan pada lokasi penelitian sudah sesuai standar yaitu bambu dengan bentuk yang berbeda-beda, ada yang bersusun diletakkan di rak dan ada pula yang sudah dirakit secara permanen dan setelah ulat naik alatnya digantungkan. Pemberian perlakuan pada saat pengokonan yang umum dilakukan berupa perlindungan terhadap ulat, agar kondisinya aman pada saat mengokon. Hal ini dilakukan karena rumah ulat yang digunakan sehari-hari biasanya terbuka dan dindingnya hanya berupa kain yang menyerupai jaring dan pada saat mengokon biasanya jaring diganti dengan terpal.

Dilihat dari aspek produksi, ternyata produksi kokon rata-rata di lokasi penelitian berkisar 20$40 \mathrm{~kg} / \mathrm{kotak}$. Produksi tersebut lebih rendah dari standar yaitu 30-40 kg/kotak. Produksi kokon sangat tergantung pada berbagai faktor di antaranya iklim saat pemeliharaan ulat berlangsung.

Waktu pemeliharaan adalah jangka waktu yang dibutuhkan untuk memelihara ulat sutera mulai dari hakitate sampai mengokon. Lama atau singkatnya jangka waktu pemeliharaan ini biasanya sangat dipengaruhi oleh kondisi biofisik, terutama cuaca. Bila cuaca panas terutama musim kemarau biasanya umur ulat lebih pendek dibanding musim hujan. Di daerah dengan ketinggian sekitar $500 \mathrm{~m} \mathrm{dpl} \mathrm{cuaca} \mathrm{biasanya} \mathrm{lebih}$ sejuk walaupun musim kemarau dan umur ulat menjadi lebih panjang, yaitu berkisar 27-30 hari. Hal ini sudah sesuai dengan standar. Jangka waktu pemeliharaan yang panjang, biasanya akan berpengaruh pada jumlah pakan yang dibutuhkan dan juga tenaga kerja yang digunakan. Namun, jangka waktu pemeliharaan yang panjang akan memberikan nilai produksi positif berupa ukuran dan berat kokon yang lebih tinggi dibanding waktu pemeliharaan yang pendek.

\section{Strategi Pengembangan Usaha Persutera- an Alam}

Dalam rangka peningkatan produksi ulat sutera beberapa upaya yang dapat dilakukan, antara lain:

\section{Peningkatan keterampilan dan kewirausa- haan petani dalam budidaya ulat sutera}

Umumnya petani lebih mengandalkan pengalaman dalam usaha budidaya murbei dan ulat sutera. Untuk itu, petani perlu dibekali dengan pengetahuan dan keterampilan yang mendukung peningkatan produksi dan menekan biaya produksi sebagaimana dikemukakan oleh Patil et al. (2009) bahwa dengan memperhatikan teknik pemberian pakan dan menjaga sanitasi dalam budidaya ulat sutera dapat membantu mengurangi biaya dan tenaga kerja.

\section{Penggunaan jenis ulat sutera unggul dan tanaman murbei unggul}

Usaha untuk meningkatkan produksi benang sutera dimungkinkan dapat tercapai apabila menggunakan jenis murbei dan ulat sutera yang unggul (hasil persilangan). Sampai saat ini pemelihara ulat sutera umumnya memberikan pakan berupa jenis-jenis murbei yang tersedia karena cenderung lebih mementingkan kuantitas daripada kualitasnya. Padahal hasil penelitian menunjukkan bahwa penggunaan jenis murbei dan ulat sutera unggul atau hasil persilangan dapat mempengaruhi rendemen pemeliharaan dan bobot kokon yang dihasilkan (Nurhaedah et al., 2006). Selain itu, tanaman murbei hasil persilangan memiliki keunggulan dalam hal produksi daun dan kandungan nutrisi yang lebih tinggi (Santoso, 2000).

\section{Teknik dan waktu pelaksanaan desinfeksi yang tepat sesuai kondisi wilayah}

Di antara beberapa faktor penyebab kegagalan yang paling dominan dan sulit diprediksi dalam budidaya ulat sutera adalah munculnya berbagai penyakit pada saat pemeliharaan ulat sutera. Bahkan, sering terjadi penyakit tidak muncul pada fase awal pemeliharaan ulat tetapi muncul pada saat ulat menjelang mengokon yang dapat dikatakan sebagai periode akhir dalam pemeliharaan ulat sutera.

Desinfeksi adalah sebuah tindakan yang dilakukan dalam pemeliharaan ulat sutera untuk mendapatkan kondisi yang bebas penyakit sebagaimana dikemukakan oleh Benchamin (1987) bahwa desinfeksi memiliki peranan penting dalam budidaya ulat sutera yang bebas patogen.

Desinfeksi dimaksudkan untuk mencegah berkembangnya penyakit, baik di dalam maupun di luar ruangan pemeliharaan, terutama penyakit yang disebabkan oleh cendawan. Desinfeksi juga merupakan suatu tindakan preventif berupa tindakan desinfeksi sebelum, selama, dan setelah pemeliharaan ulat sutera berlangsung. Hasil penelitian Anwar (1989) dalam Atmosoedarjo et al. (2000) menunjukkan bahwa dengan perlakuan 
desinfeksi pada ruang, alat, dan tubuh ulat sutera dapat menghasilkan kokon sebesar 27,417 kg kokon/kotak, sedangkan tanpa perlakuan desinfeksi hanya sebesar 19,533 kg kokon/kotak.

\section{Teknik budidaya ulat sutera dan pascapa- nen yang tepat sesuai kondisi lokasi}

Teknik budidaya merupakan teknik pemeliharaan ulat sutera mulai dari menetas hingga membentuk kokon. Sedangkan teknik pascapanen adalah teknik yang digunakan dalam kegiatan setelah panen kokon yang turut menentukan kualitas benang kokon dan benang sutera yang dihasilkan. Teknik budidaya dan pascapanen yang sesuai kondisi lokasi perlu diperhatikan karena hasil pengamatan Budisantoso (1997) menunjukkan bahwa petani cenderung meninggalkan teknis budidaya ulat sutera dan pascapanen yang direkomendasikan oleh petugas lapangan atau penyuluh yang berakibat kokon yang dihasilkan berkualitas rendah.

\section{KESIMPULAN}

\section{A. Kesimpulan}

1. Kondisi biofisik di Desa Sudu, Kecamatan Alla, Kabupaten Enrekang cukup optimal untuk budidaya ulat sutera. Suhu berkisar $20-23^{\circ} \mathrm{C}$ dan kelembaban antara $70-85 \%$.

2. Praktik budidaya murbei dan ulat sutera yang dilakukan masyarakat dilakukan berdasarkan pengalaman. Praktik budidaya tanaman murbei yang belum memenuhi standar adalah jarak tanam yang lebih rapat yaitu $30 \times 30 \mathrm{~cm}$; standar jarak tanam adalah $100 \times 50 \mathrm{~cm}$. Pemeliharaan ulat sutera yang belum memenuhi standar adalah frekuensi pemberian pakan 2 kali dibandingkan dengan standar 3-4 kali sehari, perlakuan desinfeksi 2 kali per periode masih belum memenuhi standar mengingat tingginya serangan penyakit karena kelembaban yang tinggi.

3. Jumlah produksi rata-rata kokon yang dihasilkan dari praktik masyarakat masih di bawah standar yaitu 20-40 kg dibandingkan dengan standar 30-40 kg/kotak.

\section{B. Saran}

Untuk meningkatkan produktivitas budidaya murbei dan ulat sutera di desa Sudu Kecamatan Alla Kabupaten Enrekang perlu ditingkatkan kegiatan penyuluhan oleh pemerintah daerah agar terjadi adopsi teknologi budidaya murbei dan ulat sutera. Teknik budidaya tanaman murbei meliputi pengaturan jarak tanam dan teknik pemangkasan tanaman. Teknik pemeliharaan ulat meliputi pemisahan jenis pakan, penggunaan murbei hasil persilangan, dan desinfeksi serta pemberian pakan yang tepat.

\section{DAFTAR PUSTAKA}

Atmosoedarjo. S., J. Kartasubrata, M. Kaomini, W. Saleh dan W. Murdoko. 2000. Sutera Alam Indonesia. Yayasan Sarana Wana Jaya. Jakarta.

Balai Persuteraan Alam. 1997. Pedoman Budidaya Sutera. Direktorat Jenderal Reboisasi dan Rehabilitasi Lahan. Departemen Kehutanan.

Balai Persuteraan Alam. 2008. Statistik Pembangunan Balai Persuteraan Alam. Gowa. Direktorat Jendral RLPS Departemen Kehutanan.

Benchamin, K.V. 1987. Disinfection and Hygiene. A Handbook for Sericulture Extension Workers. Central Sericultural Research and Training Institute, Mysore, p.87-92.

Budisantoso, H. 1997. Pengaruh Adopsi Teknologi pada Faktor-Faktor Produksi Sutera Alam di Soppeng Sulawesi Selatan. Buletin Penelitian Kehutanan Vol 2. No 4. Balai Penelitian Kehutanan Ujung Pandang.

B.R. Patil, K.K. Singh, S.E. Pawar, L. Maarse and J. Otte. 2009. Sericulture: An Alternative Source of Income to Enhance the Livelihoods of Small-scale farmers and Tribal Communities. Resarch Report. Pro-Poor Livestock Policy Initiative: A Living Livestock. India Sericulture.

Direktorat Jenderal Rehabilitasi Lahan dan Perhutanan Sosial. 2006. Pembinaan dan Pengembangan Sektor Hulu Persuteraan Alam. Makalah disampaikan pada Temu Usaha Persuteraan Alam. Makassar.

Nurhaedah, A. Rizal, P. Kusumedi, A. Hermawan dan W. Isnan, 2006. Pengelolaan Sutera Alam di Sulawesi Selatan. Laporan Hasil Penelitian. Balai Penelitian dan Pengembangan Kehutanan Sulawesi.

Nurhaedah, H. Budisantoso dan W. Isnan. 2006. Pengaruh murbei (Morus spp.) dan ulat sutera persilangan (Bombyx mori Linn.) terhadap kualitas ulat, kokon dan serat sutera. Jurnal Penelitian Hutan dan Konservasi Alam III (1): 65-73. Bogor.

Maturidy, A.F., 2011. Preferensi Pelaku Usaha dalam Pengembangan Persuteraan Alam di Provinsi Sulawesi Selatan. Jurnal Pasca Sarjana Universitas Hasanuddin. Makassar. 
Omura. 1980. Silkworm Rearing. Japan Tokyo: Fuji Publishing Co.ltd.

Rasyid. 1996. Dinas Perhutanan dan Konservasi Tanah/Dinas Kehutanan TK.II Hubungannya dengan Dinas Persuteraan Alam TK.I. Paper Lokakarya Pengembangan Persuteraan Alam di Ujung Pandang.

Santoso, B. 2000. Produksi dan Kandungan Nutrisi Daun Beberapa Varietas Murbei. Buletin
Penelitian Kehutanan 6(2):48-57. Balai Penelitian Kehutanan Ujung Pandang.

Samsijah dan A. Lincah. 1992. Petunjuk Teknis Budidaya Ulat sutera (Bombyx mori L.). Pusat Penelitian dan Pengembangan Hutan. Bogor.

Sunanto, H. 1997. Budidaya Murbei dan Usaha Persuteraan Alam. Kanisius. Yogyakarta.

Tohir, M. 1995. Seuntai Pengetahuan tentang Usaha Tani Indonesia. Gramedia. Jakarta. 